\title{
PCBN Tool Wear for Hard Materials Based on Thermodynamics Principals
}

\author{
Fang Shao ${ }^{*}, 1$, Yuting Wang ${ }^{2}$, Yingqun Xiao ${ }^{3}$, Lihua Xiao ${ }^{4}$ and Kesheng Zhang ${ }^{5}$ \\ ${ }^{I}$ School of Mechanical Engieering, Guizhou Institute of Technology, Guiyang, China \\ ${ }^{2}$ School of Finance Management, Shanghai International Business and Economics University, Shanghai, China \\ ${ }^{3}$ School of Electrical Engieering, Guizhou Institute of Technology, Guiyang, China \\ ${ }^{4}$ School of Materials and Metallurgical Engineering, Guizhou Institute of Technology, Guiyang, China \\ ${ }^{5}$ School of Information Engieering, Guizhou Institute of Technology, Guiyang, China
}

\begin{abstract}
The temperature rise exceeds over $1000^{\circ} \mathrm{C}$ in cutting process while working with PCBN tools high speed machining. This intense temperature results in wearing of tools and thus diffusion and oxidation are mainly responsible for wearing. This paper proposes the oxidation and diffusion wearing for PCBN cutting tools and analysis has been carried out considering thermodynamics principles. The next step is to find out dissoluation concentration of PCBN tool materials. The temperature range is different for these materials. The Gibbs free energy criterion is utilized for analysis purposes and validates the formed diffusion reaction rules in extreme temperature scenario. The PCBN tools were used for carrying out machining tests at different speeds $50,95,100$ and $180 \mathrm{~m} / \mathrm{min}$, feed of $0.1,0.2$ and depth of cut was $0.1,0.8$, 1 , and $1.5 \mathrm{~mm}$ respectively on controlled lathe machine PUMA300LM. It was revealed that experimentals results matches with theoratical data. These findings will be utilized for future reference for tools designing and material selection.
\end{abstract}

Keywords: Diffusion wear, Gibbs free energy criterion, machining tests, oxidation wear, PCBN tool wear.

\section{INTRODUCTION}

The cutting process has major challenges like tools diffusion which results in degradation of performance and surface smoothness. It also results in chattering, damaging of machine parts, tools, workpiece and so on [1].

PCBN has proven to be an effective engineering material for high speed machining because of iron and its alloys properties i.e. heat resistance, strength, thermal conductivity and inertial chemical characteristics [2]. The tool waering process results in more complications and challenges with rise in temperature and speed [3-7]. The damage and wear resulting from this high speed machining is very different from the common speed machining process [8]. The different failure mechanism can happen during poor working conditions in high speed machining environments as compared to classical cutting mechanisms and thus the consequences for tools wearing and damages are increased by manifold.

Non-linear and coupling effects are also responsible for wearing of tools. Thermodynamics theory can be applied for these non linear processes and it has proven to be very effective and feasible for analysis as well. The research based on thermodynamical principles is very limited.
This paper considers PCBN tools wear for high speed advanced cutting mechanism based on thermodynamical principles and also analysis of parameters considering oxidation and diffusion wear rules are carrid out. This research will also provide reference for design and optimization for different tool materials.

\section{PCBN DIFFUSION WEARING FOR CERAMIC TOOLS}

The absolute enthalpies $\mathrm{H} \odot=\mathrm{H} \odot \mathrm{T}-\mathrm{H} \odot 298+\mathrm{H} \odot 298$ are computed considering at different temperature conditions comparing to the relative enthalpies $\mathrm{H} \odot \mathrm{T}-\mathrm{H} \odot 298$ for $\mathrm{BN}$, diamond $\mathrm{C}, \mathrm{Al}_{2} \mathrm{O}_{3}$ and $\mathrm{Si}_{3} \mathrm{~N}_{4}$ are produced by using thermodynamics data table [10] as shown in Table $\mathbf{1}$ and Fig. (1).

\section{1. $\mathbf{A l}_{2} \mathrm{O}_{3}$ Ceramic Tool Material Solubility in Workpiece}

Solubility of PCBN tools when respectively machining steel material, titanium alloy, and pure nickel are presented in Table 2 and Fig. (2).

\section{EXPERIMENTAL SETUP}

\subsection{Devices Used for Experiment}

PUMA300LM lathe machine controlled numerically. 
Table 1. The absolute enthalpies of $\mathrm{BN}$, Diamond $\mathrm{C}, \mathrm{Al}_{2} \mathrm{O}_{3}$ and $\mathrm{Si}_{3} \mathrm{~N}_{4}$.

\begin{tabular}{|c|c|c|c|c|c|c|c|c|}
\hline \multirow{2}{*}{ Temperature/K } & \multicolumn{2}{|c|}{$\mathbf{B N}$} & \multicolumn{2}{c|}{$\mathbf{C}$} & \multicolumn{2}{c|}{$\mathbf{A l}_{2} \mathbf{O}_{3}$} & \multicolumn{2}{|c|}{$\mathbf{S i}_{3} \mathbf{N}_{4}$} \\
\cline { 2 - 9 } & $H_{T}^{e}-H_{598}^{e}$ & $H_{T}^{e}$ & $H_{T}^{e}-H_{298}^{e}$ & $H_{T}^{e}$ & $H_{T}^{e}-H_{298}^{e}$ & $H_{T}^{e}$ & $H_{T}^{e}-H_{298}^{e}$ & $H_{T}^{e}$ \\
\hline \hline 298 & 0 & -252295 & 0 & 1883 & 0 & -1675274 & 0 \\
\hline 300 & 25 & -255570 & 12 & 1895 & 158 & -1675116 & 198 & -7445754 \\
\hline 400 & 2008 & -250287 & 871 & 2754 & 9039 & -1666235 & 10768 & -733984 \\
\hline 500 & 4907 & -247388 & 2069 & 3952 & 19151 & -1656123 & 22430 & -722322 \\
\hline 600 & 8338 & -243957 & 3501 & 5384 & 30011 & -1645263 & 35020 & -709732 \\
\hline 700 & 12135 & -240160 & 5125 & 7009 & 41411 & -1633863 & 48437 & -696315 \\
\hline 800 & 16217 & -236078 & 6919 & 8802 & 53247 & -1622027 & 62605 & -682147 \\
\hline 900 & 20538 & -231757 & 8868 & 10751 & 65408 & -1609866 & 77456 & -667296 \\
\hline 1000 & 25070 & -227225 & 10968 & 12851 & 77795 & -1597479 & 92928 & -651824 \\
\hline 1100 & 29796 & -222499 & 13212 & 15095 & 90372 & -1584902 & 108962 & -635790 \\
\hline 1200 & 34704 & -217591 & 15597 & 17480 & 103115 & -1572159 & 125501 & -619251 \\
\hline
\end{tabular}

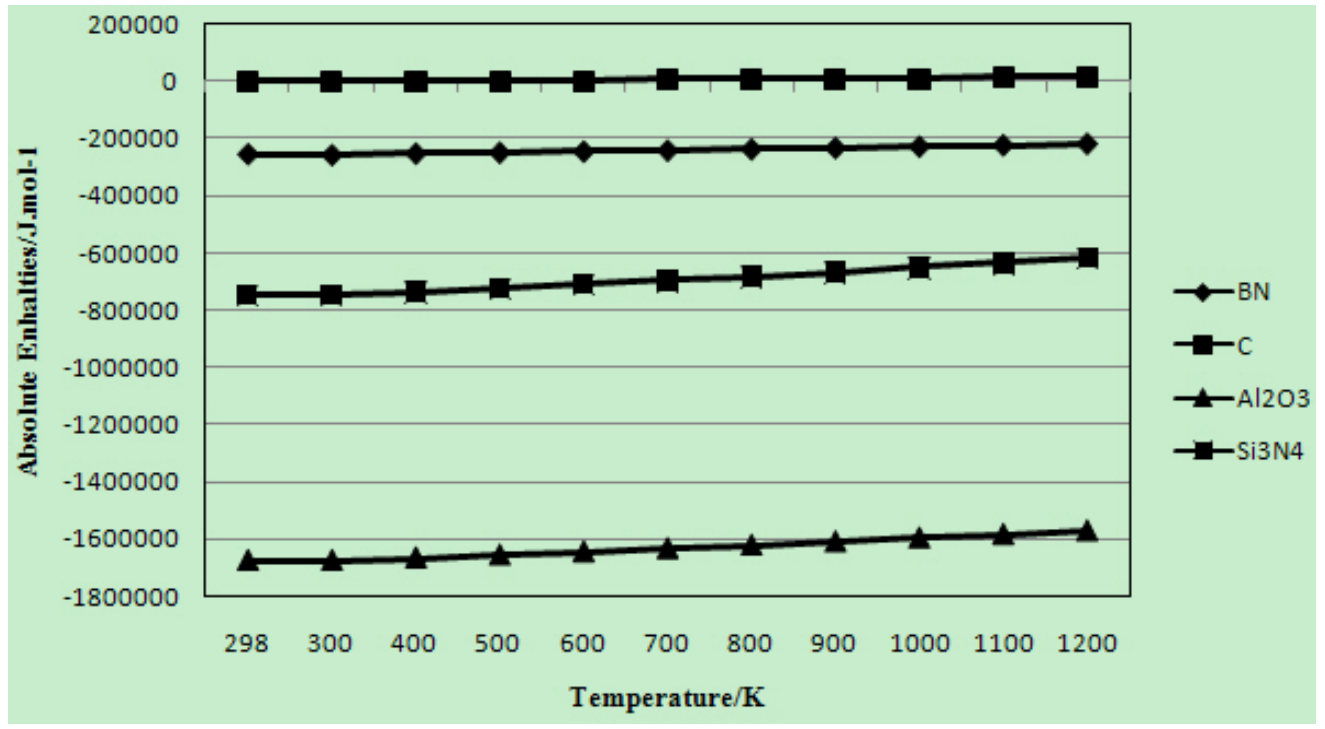

Fig. (1). Absolute enhaltpies at different temperatures.

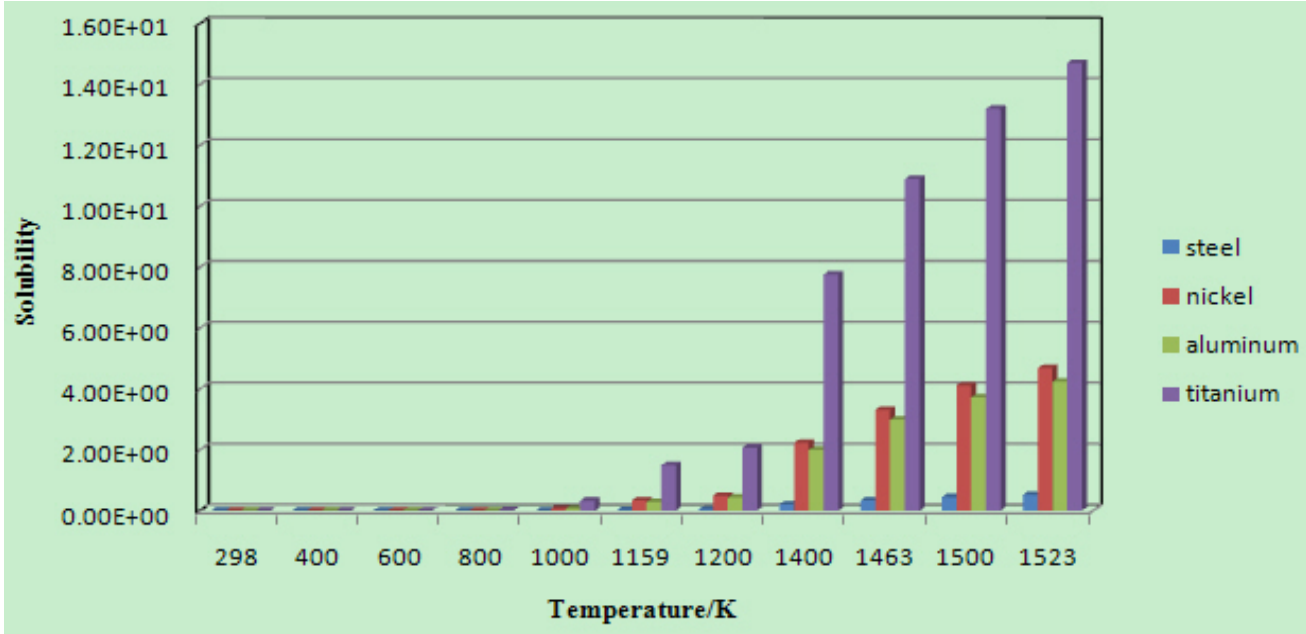

Fig. (2). PCBN tools solubility in typical workpiece materials. 
Table 2. Solubility of PCBN tool when machining typical materials - carbon steel, titanium alloy and aluminum alloy at different temperature $\left(\mathrm{mol} / \mathrm{m}^{3}\right)$.

\begin{tabular}{|c|c|c|c|c|c|c|c|c|c|c|c|}
\hline Temperature/K & 298 & 400 & 600 & 800 & 1000 & 1159 & 1200 & 1400 & 1463 & 1500 & 1523 \\
\hline $\begin{array}{c}\text { Gibbs free } \\
\text { energy of BN }\end{array}$ & -226726 & -217401 & -199117 & -180833 & -162549 & -148013 & -144265 & -125981 & -120222 & -116839 & -114736 \\
\hline Steel & $5.61 \mathrm{E}-20$ & $5.79 \mathrm{E}-14$ & $4.16 \mathrm{E}-08$ & $3.52 \mathrm{E}-05$ & $2.01 \mathrm{E}-03$ & $1.85 \mathrm{E}-02$ & $2.99 \mathrm{E}-02$ & 0.205 & 0.337 & 0.443 & 0.522 \\
\hline Nickel & $4.15 \mathrm{E}-15$ & $2.46 \mathrm{E}-10$ & $1.09 \mathrm{E}-05$ & $2.30 \mathrm{E}-03$ & $5.69 \mathrm{E}-02$ & 0.331 & 0.484 & 2.23 & 3.31 & 4.11 & 4.68 \\
\hline aluminum & $2.52 \mathrm{E}-15$ & $1.69 \mathrm{E}-10$ & $8.50 \mathrm{E}-06$ & $1.91 \mathrm{E}-03$ & $4.90 \mathrm{E}-02$ & 0.291 & 0.427 & 2.00 & 2.99 & 3.72 & 4.24 \\
\hline Titanium & $1.45 \mathrm{E}-12$ & $1.93 \mathrm{E}-08$ & $2.00 \mathrm{E}-04$ & $2.04 \mathrm{E}-02$ & 0.326 & 1.49 & 2.07 & 7.76 & 10.9 & 13.2 & 14.7 \\
\hline
\end{tabular}

\subsection{Workpiece Materials}

Aluminum alloy of these specifications: hardness value is $115 \mathrm{HBW}$, diameter value is $\varnothing 54.5 \mathrm{~mm}$; stainless steel having hardness $184 \mathrm{HBW}$, diameter is $\varnothing 47 \mathrm{~mm}$; abrasion resistant of cast iron MT-4 cast iron (cast iron for short hereinafter), hardness is $184 \mathrm{HBW}$, diameter is $\varnothing 42 \mathrm{~mm}$; No. 35 steel, rigidity value is $169 \mathrm{HBW}$, diameter is $\varnothing 48 \mathrm{~mm}$; pure nickel, rigidity is $51.9 \mathrm{HBW}$, diameter is $\varnothing 28 \mathrm{~mm}$; titanium alloy, rigidity is $41.9 \mathrm{HBW}$, diameter is $\varnothing 21 \mathrm{~mm}$. The details of workpiece components are shown as in Tables 3-6 [11].

\subsection{Tools: GE Tools Produced in America}

\subsubsection{Cutting Mechanism}

The Tables 3-6 descibes the different values of parameters utilized for cutting process on workpiece materials. The PCBN tools having different cutting speeds 10,150 and $250 \mathrm{~m} / \mathrm{min}$ were utilized and cut depth of 1,2 , 2.5 and $5 \mathrm{~mm}$ were considered for numerically controlled PUMA300LM lathe machine. These all experiments were carried out in the dry conditions and no fluid was used for 15 min. The handheld Infrared is used for the measurement of the cutting temperature and results are presented in Table 7.

The diffusion and oxidation surface are analyzed using line scanning by element wear character, points from the bottom of wear region of material were selected to make energy spectrum analysis for aluminum, oxygen and titanium. For decreasing pollution effects from the surface, line scanning is applied on the surfaces of blades. The line scanning results from these experiments for aluminum, oxygen and titanium tools material employing machining nickel, aluminum alloy, 35 steel and cast iron is depicted in Figs. (3-19).

\section{RESULTS AND DISCUSSION}

\subsection{Temperature Cutting Analysis}

The elements present in tool materials were diffused at uneven rates at the surface edges. If scan map is closely observed, the locations of low end of the curve and the high nitrogen content of the curve were amongst the top of the curve.

From Figs. (9-15), it can be concluded that rank and flank faces pervaded when PCBN tools are employed for

Table 3. Chemical components of cast iron (\%).

\begin{tabular}{|c|c|c|c|c|c|c|}
\hline Element & $\mathrm{C}$ & $\mathrm{Si}$ & $\mathrm{S}$ & $\mathrm{P}$ & $\mathrm{Cr} \mathrm{Ni} \mathrm{Cu} \mathrm{Al} \mathrm{Mo} \mathrm{V}$ & $\mathrm{Fe}$ \\
\hline Content & 3.38 & 2.1 & 0.121 & 0.072 & Little & Other \\
\hline
\end{tabular}

Table 4. Chemical components of stainless steel (\%).

\begin{tabular}{|c|c|c|c|c|c|c|c|c|}
\hline Element & $\mathrm{Cr}$ & $\mathrm{Ni}$ & $\mathrm{C}$ & $\mathrm{Si}$ & $\mathrm{Mn}$ & $\mathrm{P}$ & $\mathrm{S}$ & $\mathrm{Fe}$ \\
\hline Content & 16.63 & 4.7 & 0.072 & 0.488 & 7.692 & 0.027 & 0.004 & Other \\
\hline
\end{tabular}

Table 5. Chemical components of 35 steel (\%).

\begin{tabular}{|c|c|c|c|c|c|c|c|c|}
\hline Element & $\mathrm{C}$ & $\mathrm{Si}$ & $\mathrm{Mn}$ & $\mathrm{S}$ & $\mathrm{P}$ & $\mathrm{Cr}$ & $\mathrm{Ni}$ & $\mathrm{Fe}$ \\
\hline Content & 0.384 & 0.213 & 0.564 & 0.035 & 0.036 & 0.25 & 0.25 & $\mathrm{Other}$ \\
\hline
\end{tabular}

Table 6. Chemical components of aluminum alloy (\%).

\begin{tabular}{|c|c|c|c|c|c|c|c|c|c|}
\hline Element & $\mathrm{Si}$ & $\mathrm{Cu}$ & $\mathrm{Mg}$ & $\mathrm{Ni}$ & $\mathrm{Mn}$ & $\mathrm{Ti}$ & $\mathrm{Fe}$ & $\mathrm{Zn}$ & $\mathrm{Al}$ \\
\hline Content & $11.5-13.0$ & $0.8-1.3$ & $0.8-1.3$ & $0.8-1.3$ & $\leq 0.15$ & $\leq 0.2$ & $\leq 0.7$ & $\leq 0.2$ & Other \\
\hline
\end{tabular}

Nickel is pure nickel; titanium alloy consists of $73.68 \%$ titanium and $26.32 \%$ aluminum. 
Table 7. Cutting condition and measurement results.

\begin{tabular}{|c|c|c|c|c|c|}
\hline Workpiece Material & $\mathbf{a}_{\mathbf{p}}(\mathbf{m m})$ & $\mathbf{f}(\mathbf{m m} / \mathbf{r})$ & $\mathbf{V}(\mathbf{m} / \mathbf{m i n})$ & Surface Roughness $(\boldsymbol{\mu m})$ & Chip Temperature $\left({ }^{\circ} \mathbf{C}\right)$ \\
\hline \hline Cast iron13 & 1.5 & 0.2 & 50 & $12.5 \rightarrow 1.6$ & 114 \\
\hline nickel14 & 1 & 0.2 & 95.4 & $12.5 \rightarrow 1.6$ & 87 \\
\hline Aluminum alloy16 & 1 & 0.2 & 180 & $1.6 \rightarrow 2.0$ & 42 \\
\hline Stainless steel17 & 0.1 & 0.1 & 100 & $0.8 \rightarrow 0.4$ & 32 \\
\hline 35steel 18 & 0.1 & 0.1 & 66 & $10 \rightarrow 2.0$ & 61 \\
\hline Titanium 15 & 0.8 & 0.2 & 10.0 & 53 \\
\hline
\end{tabular}
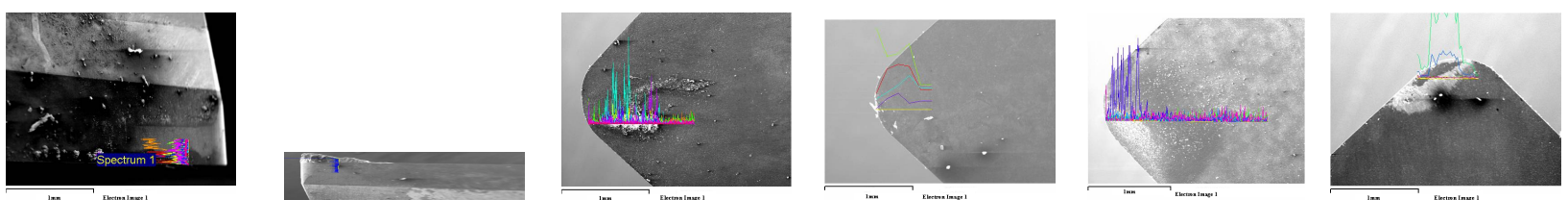

Figs. (3-8). Line scanning for machining nickel, aluminum alloy, stainless steel, 35 steel, cast iron, titanium alloy.
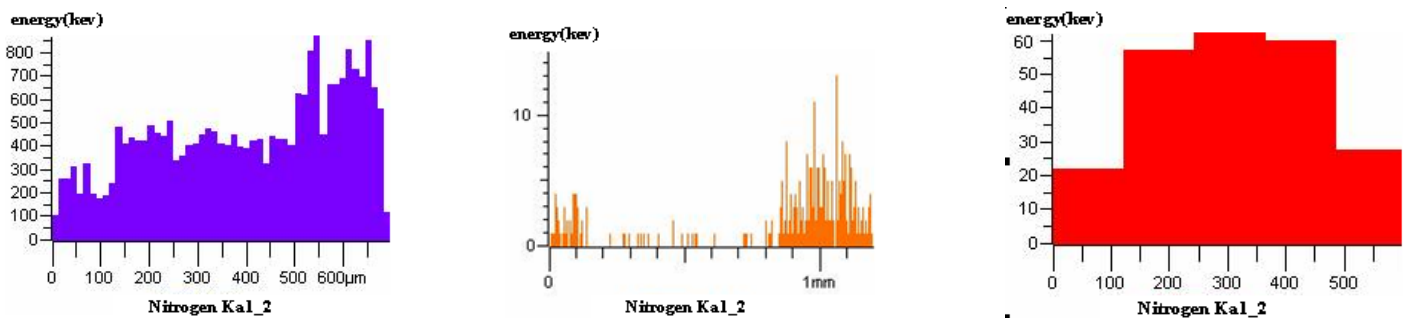

Figs. (9-11). Components of nitrogen in line scanning machining nickel, stainless and 35 steel.
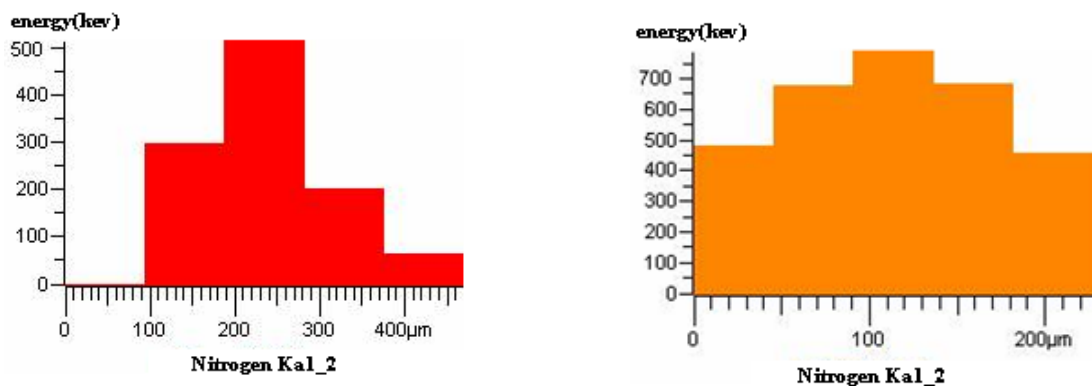

Figs. $(12,13)$. Nitrogen elements components in line scanning for machining titanium and aluminum alloy.
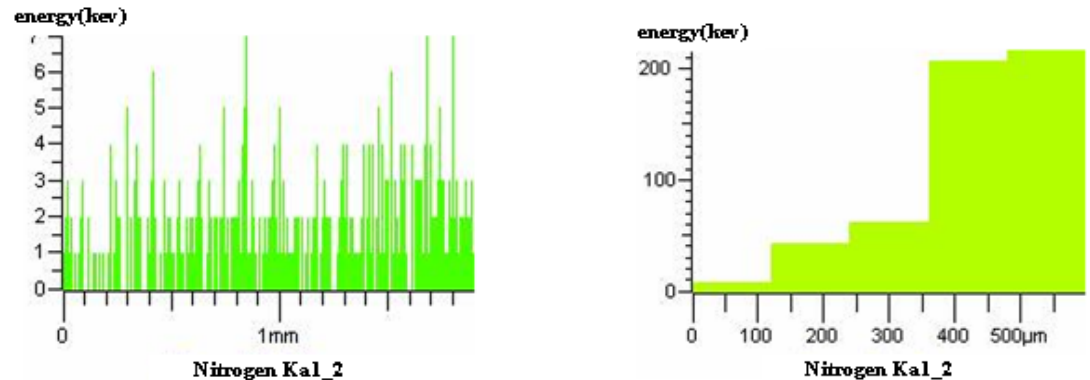

Figs. $(14,15)$. Nitrogen elements components Of rake and flank face in line scanning when machining cast iron.

cutting six kinds of materials. The flank face appeared to be bigger than rake face for both peak and energy amplitude. In cutting cast iron case, the diffusion level for nitrogen proved to be more serious in flank face. It was due to the extreme value of temperature observed in flank face of tools.
The high value of temperature in the cutting process was observed in tool's nose as well as for stainless steel cutting process which existed away from tip. It can be revealed from the Fig. (10), the intensity observed in energy was reduced considerably from the tip in case of distant object. A steady 
trend was observed and also cutting temperature was more as compared to the tool tip.

\subsection{Energy Related to Line Scanning and Chip Components Distribution}

In case of cutting process of stainless steel and 35 steel, the more uneven surfaces edges were observed in PCBN tool material as compared to cast iron. It is due to the fact that cast iron diffusion is uniformly distributed having small values and chip takes the most of the produced heat and minimum amount of heat is delivered to the tool itself. The cast iron chip temperature exceeds up to $114^{\circ} \mathrm{C}$ (measured temperature may have errors due to contrast reference values) as shown in Table 6. The other temperature values observed were much smaller as compared to the cast iron case i.e. $87^{\circ} \mathrm{C}, 42^{\circ} \mathrm{C}, 32^{\circ} \mathrm{C}, 61^{\circ} \mathrm{C}, 53^{\circ} \mathrm{C}$.

It can be revealed from Figs. $(9,11)$ that the nitrogen energy element is identical to the machining nickel and 35 steel. The wave peak amplitude is also same for both cases and the intensity level for 35 steel is having more value as compared to the nickel which is related to the PCBN tool material diffusion.
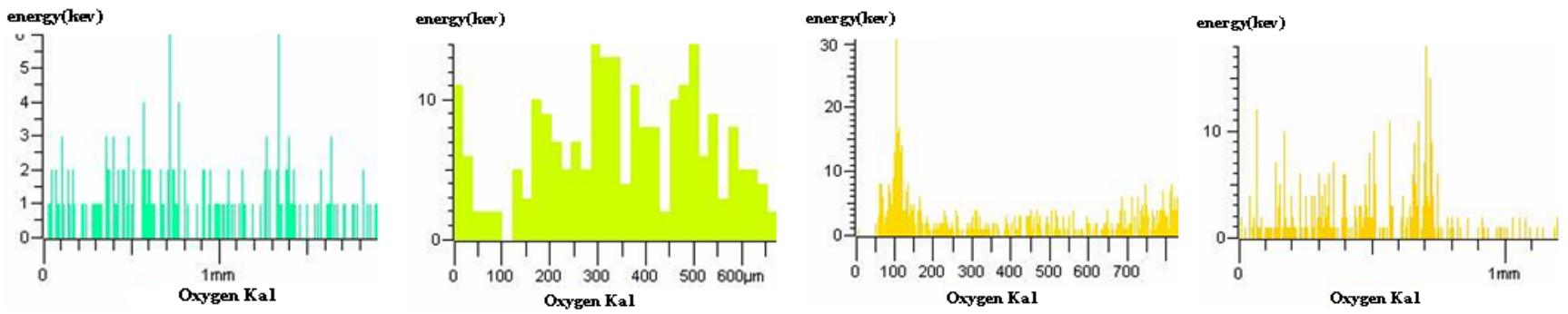

Figs. (16-19). Line scanning for oxygen element components machining cast iron, nickel, aluminum alloys and stainless steel in rake face.
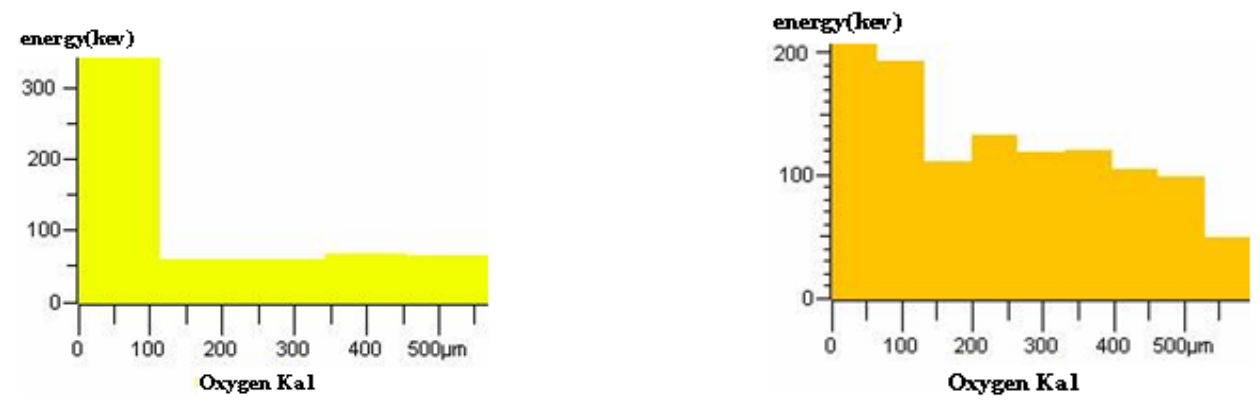

Figs. (20, 21). Line scanning for oxygen flank face element components when machining stainless steel and 35 steel.

\begin{tabular}{|c|c|c|}
\hline Elemen & (Weight) & Atomicy \\
\hline$C R$ & 31.23 & 65.20 \\
\hline OK & 2.97 & 4.66 \\
\hline Si K & 1.32 & 1.18 \\
\hline $\ln \mathbb{R}$ & 0.49 & 0.22 \\
\hline $\mathrm{Fe} \mathrm{K}$ & 63.99 & 28.74 \\
\hline Totals & 00.0 & \\
\hline
\end{tabular}

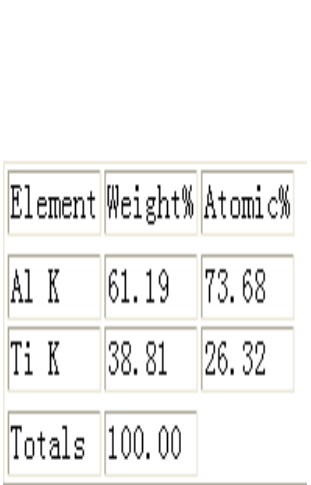

\begin{tabular}{|c|c|c|}
\hline \multicolumn{3}{|c|}{ Element Weight" Atomic } \\
\hline CK & 15.21 & 29.09 \\
\hline $0 \mathrm{~K}$ & 2.35 & 3.37 \\
\hline $\mathrm{Mg} \mathrm{K}$ & 1.05 & 0.99 \\
\hline Al K & 75.75 & 64.47 \\
\hline $\operatorname{Mn} \mathrm{K}$ & 0.71 & 0.30 \\
\hline $\mathrm{CuK}$ & 4.93 & 1.78 \\
\hline Totals & 100.00 & \\
\hline
\end{tabular}

\begin{tabular}{|c|c|c|}
\hline Element & Weight & Atomicy \\
\hline $0 \mathrm{~K}$ & 1.70 & 5.63 \\
\hline Si K & 0.53 & 1.01 \\
\hline Cr K & 14.67 & 14.90 \\
\hline $\ln \mathrm{K}$ & 7.66 & 7.37 \\
\hline $\mathrm{FeK}$ & 70.02 & 66.23 \\
\hline $\mathrm{Ni} \mathrm{K}$ & 5.41 & 4.87 \\
\hline Totals & 100.00 & \\
\hline
\end{tabular}

\begin{tabular}{|c|c|c|}
\hline Element & Weight & Atomicy \\
\hline $\mathrm{CK}$ & 10.36 & 33.13 \\
\hline $0 \mathrm{~K}$ & 2.53 & 6.08 \\
\hline $\mathrm{Al} \mathrm{K}$ & 0.91 & 1.30 \\
\hline Si K & 0.32 & 0.44 \\
\hline $\ln \mathrm{K}$ & 0.65 & 0.46 \\
\hline $\mathrm{Fe} \mathrm{K}$ & 85.22 & 58.60 \\
\hline Totals & 100.00 & \\
\hline
\end{tabular}

Figs. (22-26). Chip's element when machining nickel, titanium, aluminum and 35 steel. 
on tools chip. The intensity of oxygen for different locations at tool tip was having various values and a significant oxidation proved that large oxygen contents were present.

From Fig. (20), it is obvious that wave change graph was having abrupt changes for stainless steel machining which showed that oxidation process was severe in this case. It was due to the lower thermal conductivity of stainless steel and most of the heat was utilized for tool heating and tip was responsible for high temperature rise and oxidation process occurred abruptly without any issues. The contrast comparison between Figs. $(\mathbf{1 9}, \mathbf{2 0})$ revealed that the flank face change was more obvious than rake face change and so the rake face was easily oxidized because of having high temperature.

It is also visible from Figs. (22-26) that the oxygen element content was present in energy spectrum of five kinds of chips which showed oxidation occurred here as well. Different percentages of oxygen content in chip for 35 stainless steel with PCBN were as: 35 steel $(6.08 \%)>$ stainless steel $(5.63 \%)>$ cast iron $(4.66 \%)>$ aluminum alloy $(3.37 \%)$. From the result, it was obvious that oxidation machining for 35 steel aluminum was considerably high, It showed that the oxidation machining 35 steel was obviously high, but the aluminum alloy was more stable, while cast iron and stainless steel values lie between first two materials.

From the above analysis, it can be inferred that oxidation was more obvious and dramatic for 35 steel while the most stable value was observed for aluminum alloy. The cast iron and stainless steel values lie between these two values.

\section{CONCLUSION}

(1) All six normal material workpiece resulted in the diffusion and oxidation wear.

With increase in temperature, the solubility of tool material also exceeded exponentially. For more temperature, high diffusion was visible and the solubility order for PCBN tool workpiece materials were as follows: titanium alloy $>$ nickel $>$ aluminum alloy $>35$ steel, which was also in accordance with with the theoratical computations.

(3) The oxidation degree for machining with different PCBN materials were categorized as follows: 35 steel $>$ stainless steel $>$ cast iron $>$ aluminum alloy.

It is also evident that 35 steel oxidation was significant while aluminum alloy was more stable stainless steel and cast iron lie between the first two tool materials.

\section{CONFLICT OF INTEREST}

The authors confirm that this article content has no conflict of interest.

\section{ACKNOWLEDGMENTS}

It is gratefully acknowledges the National Natural Science Foundation(No.51465009、No.61461008); Natural Science Foundation of Guizhou Province(Guizhou Science and Technology AgencyJ[2014]2085,[2014]2086);Academician workstation of Guizhou Institute of Technology (Academician workstation(2014)4007); Department of Education of Guizhou Province 125 project;The doctoral starting up foundation of Guizhou Institute of Technology (XJGC20131201); The Bidding Projects of Guizhou Province 2013 on teaching content and course system reform(Research on international personnel training mode in General University of Guizhou Province).

\section{REFERENCES}

[1] Y. Liu, "Metal cutting theory and tool," Beijing: .Labor and Personnel Press , p.23, 1989.

[2] J.A. Arsecularatne, L.C. Zhang, and C. Montross, "Wear and tool life of tungsten carbide, PCBN and PCD cutting tools," Int. J. Mach. Tools Manuf., vol. 46, no. 5, pp. 482-491, 2006.

[3] W. Ji, X. Liu, H. Li, H. You, and M. Fan, "Research of PCBN tool wear mechanism in turning Ni-based superalloy," Adv. Mater. Res., vol. 820 , pp. 185-189, 2013.

[4] N. Ånmark, T. Björk, A. Ganea, P. Ölund, S. Hogmark, A Karasev, and P. G. Jönsson, "The effect of inclusion composition on tool wear in hard part turning using PCBN cutting tools," Wear, vol. 5, no. 334-335, pp. 13-22, 2015

[5] O. Gutnichenko, V. Bushlya, J. Zhou, and J. E. Ståhl, "Influence of cutting speed and tool wear on vibrations and process stability when turning Inconel 718 with PCBN tools," Int. J. Manuf. Res., vol. 2, no. 9, pp. 173-193, 2014.

[6] H.D. Yang, N. Liu, Z. Ding, Z.G. Zhu, and C.G. Zhang, "Wear behavior of PCBN tool in high speed turning TC4," Adv. Mater. Res., vol. 426, pp. 344-347, 2012.

[7] R. M'Saoubi, M.P. Johansson, and J.M. Andersson, "Wear mechanisms of PVD-coated PCBN cutting tools," Wear, vol. 1-2, no. 302, pp. 1219-1229, 2013.

[8] G. Su, Z. Liu, L. Li, and B. Wang, "Influences of chip serration on micro-topography of machined surface in high-speed cutting," Int. J. Mach. Tools Manuf., vol. 2, no. 89, pp. 202-207, 2015.

[9] Z. Dai, M. Wang, and Q. Xue, "Introduction to tribothermodynamics," Beijing: National Defence Industry Press, pp. $146,2002$.

[10] D. Ye, and J. Hu, "Practical handbook of thermodynamic data of inorganics," Beijing: Metallugy Industry Press, pp. 12, 2002.

[11] D. Cheng, "Mechanical design handbook," Beijing, Chemical Industry Press, vol. 1, pp. 432, 1993. 